\title{
COMPETÊNCIA INFORMACIONAL DO BIBLIOTECÁRIO NO PLANEJAMENTO DE CURSOS EM EDUCAÇÃO A DISTÂNCIA
}

\author{
INFORMATIONAL COMPETENCE OF THE LIBRARIAN \\ AT THE DISTANCE EDUCATION COURSE PLANNING
}

\author{
Paula Pinheiro da Nóbrega ${ }^{a}$ \\ Silvana Maria Araújo Limab \\ Andréa Soares Rocha da Silvac \\ Priscila Barros Davidd
}

\begin{abstract}
RESUMO
Introdução: A Educação a Distância $(\mathrm{EaD})$ como práxis social estimula reflexões sobre a realidade e, consequentemente, quando necessário, pode gerar mudanças em benefício da sociedade. No entanto, para que a modalidade seja compreendida dessa maneira, é necessário o planejamento de conteúdos voltados para a reflexão crítica, alinhando-se teoria e prática. Assim, a presença do bibliotecário no planejamento tornase primordial, pois ele enquanto mediador da informação e profissional que conhece os usuários, contribui para que os estudantes saibam ler os contextos que lhes são apresentados e isso acontece com a prática da competência informacional. Objetivo: demonstrar a importância de o bibliotecário desenvolver a competência informacional para sua atuação eficiente na fase de planejamento de conteúdos EaD. Metodologia: pesquisa bibliográfica narrativa. Resultados: Como se constata na literatura, ao organizar um curso em $\mathrm{EaD}$, a fase de planejamento pode definir o sucesso da proposta de ensino/aprendizagem. Conclusões: a presença do bibliotecário na etapa do planejamento contribui para o desenvolvimento dos alunos, tanto em nível intelectual quanto na formação da cidadania.
\end{abstract}

Descritores: Competência Informacional. Bibliotecário. Planejamento. Educação a Distância.

a Mestre em Ciência da Informação pela Universidade Federal do Ceará (UFC). E-mail: ppnjc@hotmail.com

b Mestranda do Programa de Pós-Graduação em Ciência da Informação da Universidade Federal do Ceará (UFC). E-mail: smaraujo02@yahoo.com.br

c Doutora em Educação pela Universidade Federal do Ceará (UFC). Professora do Mestrado Profissional em Saúde da Família (MPSF/UFC/RENASF) e do Programa de Pós-Graduação em Ciência da Informação (PPGCI/UFC). E-mail: andreasrs07@gmail.com

d Doutora em Educação pela Universidade Federal do Ceará (UFC). Professora do Bacharelado em Sistemas e Mídias Digitais da UFC. E-mail: priscila.pbd@gmail.com 


\section{INTRODUÇÃO}

A Educação a Distância (EaD) foi idealizada pela Universidade Aberta com o intuito de democratizar o conhecimento e tem sido uma modalidade que, por ultrapassar barreiras geográficas e por ser planejada para dar acesso ao conhecimento a todo cidadão que o desejar, vem crescendo.

Corroborando, a Associação Brasileira de Mantenedoras de Ensino Superior (2018, não paginado), em artigo publicado dia 26 de julho de 2018, afirma que:

Em pouco mais de um ano, o total de polos de ensino superior a distância subiu de 6.583 para 15.394, segundo dados do MEC (Ministério da Educação). A alta de 133\% resulta de um decreto que diminuiu as exigências para a oferta da modalidade.

A EaD se compõe de fases que correspondem à produção de cursos e conteúdos. No entanto, no presente artigo, a ênfase será dada à etapa de planejamento, pois é nela em que são definidas estratégias e ações futuras que influenciarão no êxito dos programas e, automaticamente, no alcance do principal resultado, a aprendizagem dos alunos. Para sua consecução, existem vários profissionais que compõem a equipe multidisciplinar e que desenvolvem os conteúdos, e um deles é o bibliotecário.

Sua presença colabora para estimular a qualidade de disciplinas, módulos, e, consequentemente, a melhoria do aprendizado dos alunos, pois detém um conjunto de competências e habilidades, dentre elas está a competência informacional, muito importante para contribuir com a democratização do saber, já que o bibliotecário ocupa um papel de mediador da informação e colabora para o exercício da cidadania dos estudantes.

Isso porque, ao exercer a competência informacional, o bibliotecário estimula o discente aprender a aprender, a partir do momento em que 0 profissional consegue capacitar os discentes no sentido de eles saberem escolher, analisar e manusear fontes confiáveis e seguras. E, mais, eles possam ser reflexivos, críticos e tirarem suas próprias conclusões.

Diante do exposto, o artigo trata-se de uma pesquisa bibliográfica narrativa e tem o objetivo de demonstrar a importância de o bibliotecário 
Paula Pinheiro da Nóbrega, Silvana Maria Araújo Lima, Andréa Soares Rocha da Silva, Priscila Barros David

Competência informacional do bibliotecário no planejamento de cursos em educação a distância

desenvolver a competência informacional para sua atuação eficiente na fase de planejamento de conteúdos EaD.

\section{EDUCAÇÃO A DISTÂNCIA}

Quando se fala em EaD, muitas pessoas imaginam ser uma modalidade recente e que emergiu juntamente com as tecnologias contemporâneas. No entanto, mesmo não havendo um consenso sobre a época exata em que surgiu, vários estudos apontam para tempos primórdios. Há autores, como Alves (2011), que consideram o apóstolo Paulo, seu precursor, quando distribuiu as epístolas bíblicas. O estudioso afirma ainda que, a modalidade despontou a partir de um professor nos Estados Unidos, o qual publicou um curso na Gazeta de Boston, sendo institucionalizada logo depois.

Saindo do âmbito internacional e abordando o panorama brasileiro, para Piva Jr. et al. (2011), a EaD teve como marco no país os cursos ofertados por correspondência, evoluindo para outros suportes, como rádio, televisão, até chegar à internet. Silva (2006, p. 11) afirma que, na sociedade atual em que vivemos, denominada sociedade da informação, a EaD é um instrumento eficaz para incrementar a educação online, isso porque ela vem sendo "potencializada pelas tecnologias digitais."

Diante da história da $\mathrm{EaD}$, independente dos recursos, o que se percebe da sua essência, desde o início, foi e continua sendo propiciar a construção do conhecimento entre as pessoas, quebrando barreiras sociais, econômicas e geográficas, com o intuito de democratizar o saber. Tal concepção pode ser reforçada pelos princípios que a regem.

Segundo Morés (2013, p. 77-78), a EaD está relacionada aos princípios científicos, pedagógicos e tecnológicos, que convergem para:

- maior autonomia do aluno, fazendo-o progredir do papel de receptor "alvo do processo" para o papel de ator "centro do processo", possibilitando-lhe, cada vez mais, a construção da própria aprendizagem [...];

- ampliação da participação no processo de construção do conhecimento, de modo que seja resultado de uma ação cooperativa e não individual; 
- valorização e socialização dos saberes dos alunos, construídos ao longo de suas experiências de vida [...];

- prática pedagógica tensionada pela reflexão da avaliação participativa;

- prática pedagógica da dialogicidade imbricada nos princípios da democracia participativa.

Esses princípios podem ser identificados em alguns conceitos de EaD, como é o caso de Faria e Lopes (2014), que a interpretam enquanto práxis social, ou seja, além de estudar as teorias, os alunos precisam ter uma visão prática do mundo no qual estão inseridos, refletindo sobre a realidade de modo crítico. Para os autores, se faz necessário reconhecer os estudantes enquanto sujeitos históricos, que têm em seu senso comum conhecimentos adquiridos pelas experiências de vida e somam-se à ciência.

Essa visão crítica da realidade pode trazer mudanças e melhorias para os processos educacionais. Por isso, é tão relevante na ocasião da criação de um curso a distância, seguir alguns passos que compreendem as fases da sua elaboração e desenvolvimento. Desde o planejamento até a avaliação, torna-se imprescindível a compreensão a respeito do público e do propósito do curso a ser ofertado. Pensando nisso, Falkembach (2005) estabelece algumas fases para a produção de conteúdos.

\section{FASES DO DESENVOLVIMENTO DE CURSOS EM EAD NA VISÃO DE FALKEMBACH}

A idealização de todo curso precisa de um estudo detalhado de como organizá-lo, de que forma será disponibilizado e, principalmente, para quem se destinará. E, no caso da modalidade EaD, a atenção deve ser maior, pois os interlocutores encontram-se "distantes" geograficamente e há a necessidade de existirem estratégias para que eles possam estabelecer um processo de comunicação e, automaticamente, alcancem o objetivo principal: a aprendizagem.

Por essas razões supracitadas é que Falkembach (2005) apresenta um modelo de desenvolvimento de conteúdos que dispõe de algumas fases e, cada 
uma, contribuirá para o alcance dos objetivos da aprendizagem. E, em especial, o planejamento, pois é a partir dele que se traça a programação de um curso.

Falkembach (2005, p. 3) denomina o conteúdo de courseware e explica que ele pode ser composto por "uma lição, pelo conteúdo de uma aula, um curso, um programa de treinamento, uma unidade curricular ou uma atividade didática qualquer". Percebe-se, assim, que se trata de conteúdos que serão disponibilizados a pessoas que querem continuar seus estudos, participar de aperfeiçoamentos, capacitações, dentre outros.

A sequência das etapas para o desenvolvimento dos conteúdos, segundo Falkembach (2005) está disposta em:

1) Análise e Planejamento: esta fase é a mais importante, porque ao ser projetada, repercutirá nas demais etapas e para que elas sejam bem-sucedidas, o planejamento necessita estar de acordo com: o público-alvo; quais objetivos do curso devem estar claros; conteúdos que atendam as demandas dos aprendizes, por este motivo, a relevância de se ter na equipe pessoas com expertise na área é importante; a definição do orçamento; os programas que armazenarão o curso; definição de cronograma de curso a partir de seu lançamento, as razões pelas quais o conteúdo está sendo idealizado; análise do local em que o curso será acessado, como exemplo, casas ou laboratórios e busca por uma perspectiva a respeito de como os alunos receberão a interface do curso, pois ele deve apresentar-se intuitivo e de fácil manuseio;

2) Modelagem: envolve três modelos. O primeiro trata da modelagem conceitual, momento em que são organizadas informações nas mídias. $O$ segundo é o modelo de navegação, que auxilia o acesso dos alunos aos conteúdos e deve ser interativo. O terceiro refere-se ao modelo de interface, ligado ao design das interfaces e, neste caso, é interessante que os especialistas que planejam, pensem em oferecer recursos que instiguem a percepção e o lado cognitivo dos discentes;

3) Implementação: esta fase concerne à criação ou à reutilização de recursos que embasarão a aprendizagem dos estudantes, observando a sua pertinência a esse público que está sendo atendido, se haverá inclusão de sons, 
imagens, animações, vídeos, bem como ocorre a observância dos direitos autorais;

4) Avaliação e Manutenção: fase salutar, isso porque depois do curso pronto, haverá testes para verificação de possíveis erros, inclusive gramaticais, para em seguida, se realizarem os ajustes de detalhes que foram detectados para providenciar melhorias;

5) Distribuição: traduzirá a forma pela qual o conteúdo será disponibilizado e instalado.

\section{PLANEJAMENTO DE CURSOS EM EAD}

O planejamento norteia o que se pretende realizar, e na EaD, configurase como elemento fundamental, pois deve atender as expectativas de sujeitos que, em sua maioria, não dispõem de tempo para se deslocar pessoalmente às salas por inúmeros motivos, dentre eles o trabalho ou até mesmo ausência de instituições de ensino próximo as residências.

É necessário que, ao planejar um projeto pedagógico para um curso na modalidade EaD, sejam pensados todos os detalhes, minuciosamente, objetivando satisfazer as necessidades de aprendizagem dos participantes, desde a identificação do perfil dos alunos que irão estudar até a fase de avaliação, isto é, de como foi para os discentes a experiência de ter participado.

Portanto, a conceituação de planejamento de cursos em EaD, na ótica de Junges, Povaluk e Santos (2009, p. 3296), "[...] se constitui instrumento fundamental para a garantia da qualidade e do alcance dos objetivos propostos." Ainda de acordo com os autores, para o êxito do planejamento, torna-se essencial adotar algumas ações, dentre elas: definição de datas, escolha de recursos didáticos e contratação de pessoal para compor a equipe multidisciplinar, cujos profissionais precisam empenhar-se, trabalhando com harmonia.

Além dessas ações, há elementos cruciais para que se tenha um planejamento eficiente, assim explanados a seguir, na seção 4.1. 


\subsection{Elementos Necessários ao Planejamento}

Independente de áreas, todo projeto necessita de um planejamento bem elaborado e que, principalmente, alcance os resultados esperados. Em particular, no tocante à construção de um curso na modalidade EaD, a ação de planejar torna-se essencial para definir elementos de acordo com suas etapas e conteúdos, estabelecendo, assim, contribuições efetivas para a aprendizagem dos discentes.

Segundo Paula, Ferneda e Campos Filho (2004), o planejamento é uma fase que define as razões pelas quais o curso está sendo organizado e, por meio dele, objetivos são traçados, visando o estabelecimento de estratégias tanto em nível pedagógico quanto tecnológico. Ainda para os autores, o planejamento deve adotar alguns critérios fundamentais, descritos a seguir.

Primeiramente, é necessário levar em consideração a espécie do curso a ser idealizado. Em segundo, eles explicam que se faz um exame a respeito de sua viabilização. O terceiro critério é a caracterização do público participante. A partir disso, são definidos os recursos físicos e tecnológicos que serão utilizados, considerados no quarto critério, e estes, por sua vez, definirão a composição da equipe multidisciplinar. $\mathrm{O}$ quinto critério é crucial, pois se produz um projeto pedagógico que fornecerá as orientações didático-metodológicas que nortearão os processos de ensino e aprendizagem e as relações entre os participantes (docente-discente e discente-discente). $O$ sexto critério concerne à confecção de um ambiente virtual que propicie acesso interativo (PAULA; FERNEDA; CAMPOS FILHO, 2004).

Schneider e Urbanetz (2010) destacam esses elementos cruciais para o êxito do planejamento de disciplinas em EaD como o componente que colabora para relacionamentos e interações entre docentes, estudantes e conteúdos, e tutor. Chamam atenção, também, para a relevância de se formatar a avaliação de aprendizagem de acordo com o que propõem os conteúdos, e, inclusive, frisam a adoção de metodologia para adequação de cada processo referente ao ensino/aprendizado. 
Na visão de Ota e Vieira (2012, p. 5), o planejamento dá suporte estrutural aos conteúdos dos cursos EaD e os autores consideram ser esta uma "atividade conceitual e estrutural de um curso" e responde às indagações: "a que[m] ensinar? Por que ensinar? O que ensinar? Como ensinar? Que recursos usar?". Por esta razão, o planejamento enriquece e estimula melhorias dos processos de ensino/aprendizagem.

Vale ressaltar o que cada resposta atribuída pelos autores significa para o desenvolvimento eficiente do planejamento dos conteúdos. Inicialmente, "a que[m] ensinar?" abrange os estudantes, no sentido de analisar se estes dispõem de familiaridade quanto ao uso das tecnologias e como aprendem e agem sendo autônomos.

Os autores definem o "por que ensinar?", explicando que há uma convergência dos objetivos de aprendizagem para a adoção das recomendações pertencentes aos referenciais em EaD do Ministério da Educação (MEC). A compreensão do "o que ensinar?" traduz uma facilidade para tomar decisões no que tange à escolha de conteúdos que possam exprimir conhecimentos relevantes à formação do aprendiz.

A questão "como ensinar?" trata-se da maneira pela qual o professor desperta o interesse dos alunos para aprender e, consequentemente, formular novos conhecimentos. Todavia, os autores lembram a atenção que se deve atribuir ao manuseio de instrumentos tecnológicos. Ota e Vieira (2012) perguntam, ainda, a respeito de "que recursos usar?". Essa questão decide acerca das mídias que contribuirão para a aprendizagem dos discentes, independente do suporte, como exemplos, textos, materiais iconográficos, vídeos, dentre outros, tendo o cuidado desses recursos estarem em domínio público e/ou pertencerem à própria instituição que está ofertando o curso.

Portanto, no campo educacional a distância, o planejamento oportuniza uma visão de futuro e subsidia a todos os envolvidos no processo de ensinoaprendizagem a enfrentar mudanças, encarando, então, novos desafios. Um dos desafios pode estar presente até no fato de adequação dos conteúdos conforme a caracterização e o ritmo do aluno, dessa maneira, sua mensuração se dá por 
meio da avaliação da aprendizagem e da avaliação institucional do curso (avaliação do conteúdo, dos recursos tecnológicos utilizados, da metodologia, do professor-tutor e da autoavaliação do aluno).

Ademais, para o alcance dos objetivos e metas de um planejamento de curso, a composição da equipe que irá trabalhar nas etapas que englobam todo o processo, traz em si uma grande importância, pois cada profissional com seus conhecimentos especializados agregará valores que colaborarão para a garantia da qualidade. Assim, como será visto a seguir, a atuação do bibliotecário contribuirá para o gerenciamento da informação de modo mais eficaz.

\section{ATUAÇÃO DO BIBLIOTECÁRIO NO PLANEJAMENTO}

A participação do bibliotecário no planejamento de um curso em EaD pode estar presente em diversificadas atividades e, com isso, enriquecer os programas de cursos. Enquanto profissional que gerencia, trata, organiza e dissemina a informação, uma de suas atuações nessa fase, está na construção de bibliotecas virtuais, inclusive, a respeito do tema, Mostafa (2003) relata que elas precisam ser customizadas.

Para a customização do acervo, o bibliotecário deve realizar estudos de usuários, com o intuito de traçar o perfil informacional do público que utilizará a biblioteca virtual, para fornecer as informações específicas que eles necessitam e, mais, garantir a qualidade das fontes de informação que serão consultadas pela comunidade acadêmica digital. Corroborando, Andrade-Pereira e Sanches (20--) consideram que a biblioteca online deve "apresentar bons acervos cujas informações apresentem conteúdos em diversas linguagens e com qualidade".

No momento em que se está planejando, o bibliotecário também ocupa um papel estratégico quanto à observância dos direitos autorais, isso porque, em algumas vezes os professores conteudistas escrevem textos para a composição das aulas e baseiam-se em teóricos que estudam o assunto a ser trabalhado. Assim, o bibliotecário por ter ciência a respeito da legislação, orienta os docentes no tocante ao uso adequado de materiais de acordo com a lei evitando problemas como plágio e desinformação. 


\section{Costa e Silva (2017, p. 5) ratificam:}

As relações entre os usuários e os recursos das bibliotecas digitais transformam-se, em função da natureza hipertextual, multimodal e interativa do ciberespaço. Como exemplo, questões sobre autoria e direito autoral são debatidas continuamente pelas instituições que ofertam cursos na modalidade a distância.

Além de esclarecer sobre como proceder ao usar a informação, o bibliotecário antecipa a demanda das pessoas por conhecimentos através do Serviço de Disseminação Seletiva da Informação (DSI), que tem como uma das finalidades atualizar o usuário na área em que ele demonstra interesse. A DSI pode ser planejada de modo que venha a ser disponibilizada em ambientes virtuais que ofereçam acesso fácil e intuitivo para quem a busca. O serviço instiga uma interação mais efetiva entre todos os interlocutores.

Com relação à DSI, para Eirão (2009, p. 25), "Planejar o serviço e seu funcionamento é muito mais que trabalhá-lo teoricamente, os testes e simulações de situações tornam-se imprescindíveis para a finalização do serviço." Ou seja, a informação que se pretende divulgar, realmente, deve apresentar consistência, pois como explana o autor, fazer DSI não significa distribuir apenas listas de referências, mas entregar textos, resumos e outros recursos que satisfaçam as necessidades informacionais.

Portanto, como se constata, o bibliotecário pode estar engajado em qualquer uma das fases do planejamento de um curso, módulo ou até mesmo uma disciplina desenvolvida no formato EaD, etapas as quais são classificadas por Castro e Ladeira (2009, p. 235):

[...] o planejamento e a gestão de um programa a distância deve ser visto preliminarmente sob a ótica de processos organizacionais, destacando-se especial atenção à coordenação de atividades interdependentes, executadas por equipes multidisciplinares, e desenvolvido através das seguintes etapas: i) diagnóstico e análises preliminares; ii) projeto; iii) produção; iv) implementação; e, v) avaliação.

Com o objetivo de oferecer um curso que prime pela satisfação dos participantes, a composição da equipe multidisciplinar em $\mathrm{EaD}$ que conta com o bibliotecário planejando, ganhará em vários quesitos, um deles está em sua atuação no diagnóstico e análises preliminares, cujo profissional subsidia 0 
programa ao pesquisar dados importantes sobre os estudantes, como: sondagem quanto ao que necessitam aprender, se dominam tecnologias, faixa etária, em qual cultura estão inseridos etc.

$\mathrm{Na}$ fase de projeto do curso, o bibliotecário também desenvolve atributos que cooperam para conteúdos que acrescentem saberes a cada um dos interlocutores e que estes consigam apreender as temáticas e, principalmente, tenham discernimento e edifiquem novos conhecimentos. Aqui podem ser lembrados dois momentos importantes que o profissional da informação colabora: a escolha de fontes de informações que atendam o propósito de aprendizagem dos discentes e até mesmo opinarem sobre o design, o qual deve apresentar-se intuitivo, onde o aluno alcance um grau de independência e de autonomia.

O bibliotecário dispõe de diversas habilidades e competências que permitem sua atuação na $\mathrm{EaD}$ e uma delas será vista no próximo item: a competência informacional.

\section{COMPETÊNCIA INFORMACIONAL DO BIBLIOTECÁRIO E PLANEJAMENTO EM EAD}

O mundo atual, que utiliza como ferramenta a internet para oferecer acesso às mais variadas informações, ao mesmo tempo em que franqueia a oportunidade de se ter à disposição múltiplos assuntos, cria uma situação que merece atenção, que é a velocidade da produção de informações lançadas a cada dia. Assim, emerge a urgência em filtrá-las. No entanto, para tal, há competências e habilidades que necessitam ser empregadas para solucionar 0 referido problema. E uma dessas competências é a informacional.

Historicamente, o termo competência informacional não é tão antigo. Teve suas origens nos Estados Unidos, durante os anos de 1970, com o nome de information literacy. (CAMPELLO, 2003). Dudziak (2003) fala que foi o bibliotecário Paul Zurkowski quem instituiu tal vocábulo. O autor conta que Zurkowski embasava suas concepções na ideia de que a solução para problemas estaria em recursos informacionais. Isto implica ao entendimento de 
que information e literacy são distintas. A information está representada na mente por códigos e faz parte de um contexto dentro da sociedade que utiliza processos de comunicação.

Dudziak (2003) prossegue em suas explicitações e diz que, já no caso da literacy, esta perpassa pelo despertar da criticidade, onde um indivíduo aprende por si mesmo. $O$ estudioso continua suas conjecturas e afirma que a information literacy, traduzida para o idioma português, são aplicados alguns significados, que podem ser compreendidos como: alfabetização informacional, letramento, literacia, fluência informacional e competência em informação, entretanto, o autor considera mais adequado o descritor competência informacional.

Segundo Vitorino e Piantola (2009, p. 135), a conceituação de competência informacional, atualmente, tem cada vez mais ampliado suas concepções em relação aos seus primórdios, que, antes, era compreendida como habilidades pessoais relacionadas ao manuseio de informações em meios digitais. Porém, os autores afirmam que, na presente época, outros componentes vêm sendo estudados, como na Austrália, através da Council of Australian University Librarian (CAUL), inspirada na definição da Associação Americana de Bibliotecários, que diz: "a habilidade de definir, localizar, acessar, avaliar e usar a informação de forma ética e socialmente responsável como parte de uma estratégia de aprendizado ao longo da vida."

A competência informacional torna-se uma aliada do planejamento de cursos EaD, e o bibliotecário, além da sua qualificação técnica e gerencial para lidar com a organização de conteúdos, conhece os usuários. Deste modo, pode adequar processos para que haja o aprendizado eficiente, colaborando, então, para que os estudantes aprendam a aprender, tenham discernimento da realidade e produzam suas próprias considerações.

De acordo com Carvalho e Gasque (2018, p. 108):

As pessoas precisam ser capazes de utilizar de maneira crítica e reflexiva as informações que recebem. Isso se torna possível por meio de programas de formação e capacitação para lidar com a informação, os quais deveriam estar inseridos nas escolas, universidades, empresas e organizações que desejam melhorar o desempenho. É preciso entender que buscar e usar a informação efetivamente requer o engajamento dos sujeitos 
em processos de aprendizagens, e saber mediá-los torna-se condição precípua para os profissionais que lidam com a informação, como é o caso dos bibliotecários [...].

Na modalidade de ensino EaD, a mediação é uma das ações que deve ser muito bem planejada, porque corrobora com um dos princípios da educação a distância: a autonomia, pois é preciso lembrar que, haverá ocasiões em que os alunos estarão sozinhos e necessitarão ser autodidatas para buscar as informações do seu interesse. Daí o bibliotecário, ao realizar essa mediação, orienta os sujeitos a pesquisarem em fontes seguras e confiáveis, incentivando, ainda, uma cultura independente e estimulando a democratização do saber, que também é outro princípio da EaD.

Conforme Pereira e Assis (2010, p. [5]):

Atuar como formador educacional, participante do processo de ensino e aprendizagem, desenvolvendo ações em torno da mediação entre usuários e informação, instrumentalizando-os à pesquisa, acesso e uso efetivo da informação são características indispensáveis ao bibliotecário nesse novo cenário.

Portanto, o conjunto de competências e habilidades intrínsecas à profissão do bibliotecário beneficia os programas de EaD, não apenas na fase de planejamento, mas em todas as etapas para criação de cursos.

\section{CONCLUSÃO}

Como se viu na literatura, a EaD não é tão recente, mas sempre teve o objetivo de democratizar o conhecimento, compartilhando-o. E, nos dias atuais, a internet torna-se aliada para a modalidade, devido às possibilidades de oferecer variados recursos, sem contar que as pessoas podem ter acesso a informações em qualquer lugar que estiverem. No entanto, são necessárias algumas condições para que os cursos mantenham qualidade, dentre elas está o planejamento de conteúdos.

Na fase do planejamento é que se define como o curso será elaborado e, nessa etapa, a presença do bibliotecário torna-se muito relevante, já que, ele enquanto profissional da informação, conhece os usuários e pode ajudar na construção de perfis dos discentes e, consequentemente, a aprendizagem obter 
êxito.

Para tanto, o bibliotecário ao dispor da competência informacional, contribui para mediar o conhecimento e fomentar a criticidade dos estudantes. Isso pode ser feito de várias formas, uma delas está no incentivo à pesquisa de fontes que sejam importantes para seu desenvolvimento enquanto discente e cidadão.

\section{REFERÊNCIAS}

ALVES, L. Educação a distância: conceitos e história no Brasil e no mundo. RBAAD, v. 10, p. 83-92, ago. 2011. Disponível em: http://www.abed.org.br/revistacientifica/Revista_PDF_Doc/2011/Artigo_07.pdf. Acesso em: 04 maio 2020.

ANDRADE-PEREIRA, F.; SANCHES, A. L. A. R. Bibliotecas digitais e virtuais no contexto da EaD: serviços on-line para usuários remotos. [S.I.: s.n.], [20--]. Disponível em: https://www.gapcongressos.com.br/eventos/z0070/trabalhos/final_500.pdf. Acesso em: 30 out. 2018.

ASSOCIAÇÃO BRASILEIRA DE MANTENEDORAS DE ENSINO SUPERIOR. Polos de ensino superior a distância crescem $133 \% \mathrm{em}$ um ano. Brasília, DF, 2018. Disponível em: https://abmes.org.br/noticias/detalhe/2923/polos-deensino-superior-a-distancia-crescem-133-em-um-ano. Acesso em: 2 dez. 2018.

CAMPELLO, B. O movimento da competência informacional: uma perspectiva para o letramento informacional. Ciência da Informação, v. 32, n. 3, p. 1-10, 2003. Disponível em: http://revista.ibict.br/ciinf/article/view/986/1027. Acesso em: 04 maio 2020.

CARVALHO, L. F. de; GASQUE, K. C. G. D. Formação continuada de professores e bibliotecários para o letramento informacional: a contribuição da educação a distância. TransInformação, Campinas, v. 30, n. 1, p. 107-119, jan./abr. 2018. Disponível em: http://www.scielo.br/pdf/tinf/v30n1/2318-0889tinf-30-1-0107.pdf. Acesso em: 04 maio 2020.

CASTRO, J. M. de; LADEIRA, E. S. Gestão e planejamento de cursos a distância (EaD) no Brasil: um estudo de casos múltiplos em três instituições de ensino superior. Revista Gestão e Planejamento, Salvador, v. 10, n. 2, p. 229247, jul./dez. 2009. Disponível em:

https://revistas.unifacs.br/index.php/rgb/article/view/344/771. Acesso em: 04 maio 2020. 
Paula Pinheiro da Nóbrega, Silvana Maria Araújo Lima, Andréa Soares Rocha da Silva, Priscila Barros David

Competência informacional do bibliotecário no planejamento de cursos em educação a distância

COSTA, J. M.; SILVA, I. M. M. Bibliotecas digitais na educação a distância: conexões com a percepção de estudantes. Novas Tecnologias na Educação, v. 15, n. 1, p. 1-10, jul. 2017. Disponível em:

https://seer.ufrgs.br/renote/article/view/75144/42580. Acesso em: 04 maio 2020.

DUDZIAK, E. A. Information literacy: princípios, filosofia e prática. Ciência da Informação, Brasília, DF, v. 32, n. 1, p. 23-35, jan./abr. 2003. Disponível em: http://revista.ibict.br/ciinf/article/view/1016/1071. Acesso em: 04 maio 2020.

EIRÃO, T. G. Disseminação seletiva da informação: uma abordagem. Revista Digital de Biblioteconomia e Ciência da Informação, Campinas, v. 7, n. 1, p. 20-29, jul./dez. 2009. Disponível em: http://www.brapci.inf.br/index.php/article/download/8615. Acesso em: 31 out. 2018.

FALKEMBACH, G. A. M. Concepção e desenvolvimento de material educativo digital. Novas Tecnologias na Educação, v. 3, n. 1, p. 1-15, maio 2005. Disponível em: https://seer.ufrgs.br/renote/article/view/13742/7970. Acesso em: 04 maio 2020.

FARIA, A. A.; LOPES, Luís Fernando. Práticas pedagógicas em EaD. Curitiba: InterSaberes, 2014. (Série Tecnologias Educacionais).

JUNGES, K. dos S.; POVALUK, M.; SANTOS, V. S. dos. O planejamento como elemento norteador da qualidade do processo de ensino e aprendizagem na educação a distância. In: CONGRESSO NACIONAL DE EDUCAÇÃO, 9., ENCONTRO SUL BRASILEIRO DE PSICOPEDAGOGIA, 3., 2009, Curitiba, PR. Anais [...]. Curitiba: PUCPR, 2009. Disponível em: https://educere.bruc.com.br/arquivo/pdf2009/2977_1395.pdf. Acesso em: 04 maio 2020.

MORÉS, A. Educação superior e processos de ensino e aprendizagem em EaD: os casos UCS e UFRGS. Conjectura: Filosofia e Educação, Caxias do Sul, v. 18, n. 1, p. 72-86, jan./abr. 2013. Disponível em: http://www.ucs.br/etc/revistas/index.php/conjectura/article/view/2039/1202. Acesso em: 04 maio 2020.

MOSTAFA, S. P. EaD sim, mas com qual biblioteca? Revista Digital de Biblioteconomia e Ciência da Informação, Campinas, v. 1, n. 1, p. 1-11, jul./dez. 2003. Disponível em: https://periodicos.sbu.unicamp.br/ojs/index.php/rdbci/article/view/2085/2215. Acesso em: 30 out. 2018.

OTA, M. A.; VIEIRA, P. L. Produção de conteúdos para EAD: planejamento, execução e avaliação. In: SIMPÓSIO INTERNACIONAL DE ENSINO DA LÍNGUA PORTUGUESA, 2., 2012, Uberlândia, MG. Anais [...]. Uberlândia: 
Paula Pinheiro da Nóbrega, Silvana Maria Araújo Lima, Andréa Soares Rocha da Silva, Priscila Barros David

Competência informacional do bibliotecário no planejamento de cursos em educação a distância

EDUFU, v. 2, n. 1, p. 1-13, 2012. Disponível em:

http://www.ileel.ufu.br/anaisdosielp/wp-

content/uploads/2014/07/volume_2_artigo_203.pdf. Acesso em: 04 maio 2020.

PAULA, K. C. de; FERNEDA, Edilson; CAMPOS FILHO, Maurício Prates de. Elementos para implantação de cursos à distância. Colabor@ - Revista Digital da CVA - Ricesu, v. 2, n. 7, maio 2004. Disponível em: https://pdfs.semanticscholar.org/f261/873807b8d735197fddfb9d1f141e7893e2c 9.pdf. Acesso em: 26 out. 2018.

PEREIRA, R.; ASSIS, W. S. A prática biblioteconômica sob a perspectiva da educação à distância (EAD): concepções iniciais. In: ENCONTRO DE BIBLIOTECAS UNIVERSITÁRIAS DO CENTRO-OESTE, 1., 2010, Goiânia, GO. Anais [...]. Goiânia: UFG, 2010. Disponível em:

https://files.cercomp.ufg.br/weby/up/220/o/Artigo_Wanderlice.pdf. Acesso em: 04 maio 2020.

PIVA JR., D. et al. EAD na prática: planejamento, métodos e ambientes. Rio de Janeiro: Elsevier, 2011.

SCHNEIDER, E. I.; URBANETZ, S. T. O planejamento do processo de ensino e aprendizagem na educação a distância. In: CONGRESSO INTERNACIONAL ABED DE EDUCAÇÃO A DISTÂNCIA, 16., 2010, Foz do Iguaçu, PR. Anais [...] Foz do Iguaçu: [s.n.], 2010. Disponível em:

http://www.abed.org.br/congresso2010/cd/3042010143007.pdf. Acesso em: 28 out. 2018.

SILVA, M. (org.). Educação online: teorias, práticas, legislação, formação corporativa. 2. ed. São Paulo: Edições Loyola, 2006.

VITORINO, E. V.; PIANTOLA, D. Competência informacional: bases históricas e conceituais: construindo significados. Ciência da Informação, Brasília, DF, v. 38, n. 3, p. 130-141, set./dez. 2009. Disponível em:

http://revista.ibict.br/ciinf/article/view/1236/1414. Acesso em: 04 maio 2020.

\title{
INFORMATIONAL COMPETENCE OF THE LIBRARIAN AT THE DISTANCE EDUCATION COURSE PLANNING
}

\begin{abstract}
Introduction: The Distance Education as a social praxis stimulates reflections on reality and, consequently, when necessary, can generate changes for the benefit of society. However, for the modality to be understood in this way, it is necessary to plan contents aimed at critical reflection, aligning theory and practice. Thus, the presence of the librarian in planning becomes paramount, since he as mediator of information and
\end{abstract}


professional that knows the users, contributes to the students to read the contexts that are presented to them and this happens with the practice of informational competence. Objective: to demonstrate the importance of the librarian to develop the informational competence for its efficient performance in the planning phase of the contents in Distance Education. Methodology: narrative bibliographic research. Results: As can be seen in the literature, when planning a course in Distance Education, the planning phase can define the success of the teaching/learning proposal. Conclusions: The presence of the librarian in the planning stage contributes to the students' development, both at the intellectual level and in the formation of citizenship.

Descriptors: Information Competence. Librarian. Planning. Distance Education.

\title{
COMPETENCIA INFORMACIONAL DE EL BIBLIOTECARIO EN PLANIFICACIÓN DE CURSOS DE EDUCACIÓN A DISTANCIA
}

\begin{abstract}
RESUMEN
Introducción: La Educación a Distancia $(\mathrm{EaD})$ como praxis social estimula reflexiones sobre la realidad y, consecuentemente, cuando es necesario, puede generar cambios en beneficio de la sociedad. Sin embargo, para que la modalidad sea comprendida de esa manera, es necesario la planificación de contenidos orientados a la reflexión crítica, alineándose teoría y práctica. Así, la presencia del bibliotecario en la planificación se vuelve primordial, pues él como mediador de la información y profesional que conoce a los usuarios, contribuye a que los estudiantes sepan leer los contextos que les son presentados y eso sucede con la práctica de la competencia informacional. Objetivo: demostrar la importancia de que el bibliotecario desarrolle la competencia informacional para su actuación eficiente en la fase de planificación de contenidos EaD. Metodología: investigación bibliográfica narrativa. Resultados: Como se constata en la literatura, al organizar un curso en EaD, la fase de planificación puede definir el éxito de la propuesta de enseñanza/aprendizaje. Conclusiones: la presencia del bibliotecario en la etapa de la planificación contribuye al desarrollo de los alumnos, tanto a nivel intelectual y en la formación de la ciudadanía.
\end{abstract}

Descriptores: Competencia Informacional. Bibliotecario. Planificación. Educación a Distancia.

Recebido em: 08/12/2019

Aceito em: 23/04/2020 